\title{
A Successful Industrial Academic Cooperation, Development of Closed-cell Metallic Foams
}

\author{
${ }^{1}$ Sheng-Chung Tzeng, ${ }^{1}$ Chu-Wei Lin and ${ }^{2}$ Wei-Ping Ma \\ ${ }^{1}$ Department of Mechanical Engineering, Chienkuo Technology University \\ Changhua 500, Taiwan, Republic of China \\ ${ }^{2}$ Department of Information Management, Lan-Yang Institute of Technology \\ I-Lan 261, Taiwan, Republic of China
}

\begin{abstract}
Abstarct: This investigation proposes a successful case of industrial-academic cooperation between the Chienkuo Technology University and J. King Aluminum Inc. This study was proposed by the rotating machinery and heat transfer laboratory. They studied the optimal heat transfer and structural strength of closed-cell aluminum porous material. The cooperation involved the exchange of technical skills; the determination of policies and methods for establishing a lasting relationship, to ensure mutual trust between the parties involved and the elucidation of the benefits enjoyed by both sides. This study seeks to provide a good example to local technical industrial institutions of successful industrial-academic cooperation to promote academic professional research and the establishment of empirical formulae from relevant experimental data. The results of the example are useful in designing an electronic package and cooling device will lead to the novel material applications and reduce the cost of research in related industries, improving global production and marketing, also motivates students to combine academic skills and industrial practice as part of a professional education.
\end{abstract}

Key words: Industrial-Academic Cooperation, Heat Transfer, Structural Strength, Aluminum Porous Material

\section{INTRODUCTION}

Educational institutions can enhance the quality of the education provided by learning from the practical experience of industries [1]. Industry can reduce costs by developing training techniques and other innovations through academic research [2]. J. King Aluminum Inc., founded in 1986, was an aluminum alloy provider, dedicated to providing high-quality forging and casting aluminum materials. It is one of Taiwan's top 500 manufactures. J. King has also expanded into derivative products such as porous aluminum boards and other high-tech materials.

The rotating machinery and the heat transfer laboratory of the Chienkuo Technology University was involved in this cooperation. One field of research concerns the heat transfer in porous materials. The plan for cooperation focuses on optimizing the heat transfer and structural strength of closed-cell metallic foams [3-9]. Cooling IC is the very practical application addressed herein. A higher power generation of the IC including the floating computing in CPU corresponds to a higher generated temperature and this local high temperature will damage the function of the IC. One highly efficient heat transfer technique will be developed to solve this problem.
Policy of Industrial Academic Cooperation: Researchers at the Chienkuo Technology University and J. King Aluminum Inc. cautiously discussed and evaluated the characteristics of the porous aluminum material and pre-experimental requirements. The results of the evaluation were obtained in "heat transfer experiments" and "mechanical property testing". J. King Inc. hopes to make industrial-academic cooperation the norm. The results of this study by the Chienkuo Technology University provides J King with technical development and consulting, increasing $\mathbf{J}$ King's manufacturing capacity and R. D. potential.

Analysis of Industrial Products: This study focuses on establishing the relationships between the heat transfer performance for closed aluminum porous alloy and the optimal mechanical properties in two areas: mechanical property analysis and heat transfer formulations. Related research methods and procedures are described as follows.

\section{Mechanical Property Analysis}

Compressibility Strength Test: The collapse of pore films makes their compressive strength different from that described by a general material test curve. The 


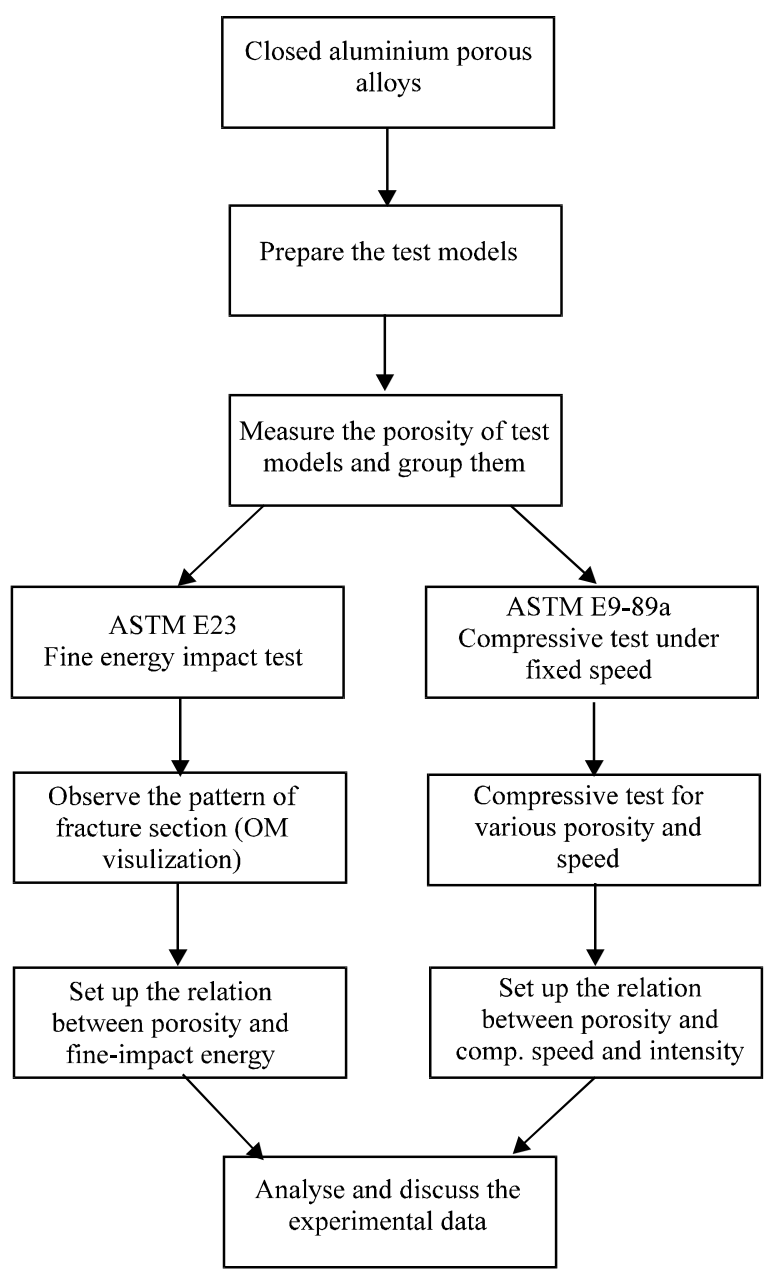

Fig. 1: Flow Chart for Performing Mechanical Property Experiments on Closed-cell Aluminium Foams

material properties of such films are between those of elastic and plastic material structures. In the low-strain region, the behavior of the material is similar to that in the linear elastic stage. When the stress reaches a peak $\left(\sigma_{\max }\right)$, the appearance of the material begins to change and the compression is transferred from external the surface to interior, in the "Plateau Stage". Afterwards, as the external compression increases, the material becomes condensed and the compressive strength increases remarkably. Finally, the material becomes an immutable solid. The results of test reveal the relationship between maximum compression strength and porosity. The mathematical relationship is:

$$
\frac{£ \mathrm{~m}}{£ \mathrm{~m}} \mathrm{i} \times \mathrm{C}\left(\frac{£ 1^{*}}{£ 1_{\mathrm{s}}}\right)
$$

where, and $\sigma_{\mathrm{s}}$ and $\rho_{\mathrm{s}}$, mean the maximum compressive intensity and the specific gravity of porous and sample materials, respectively.

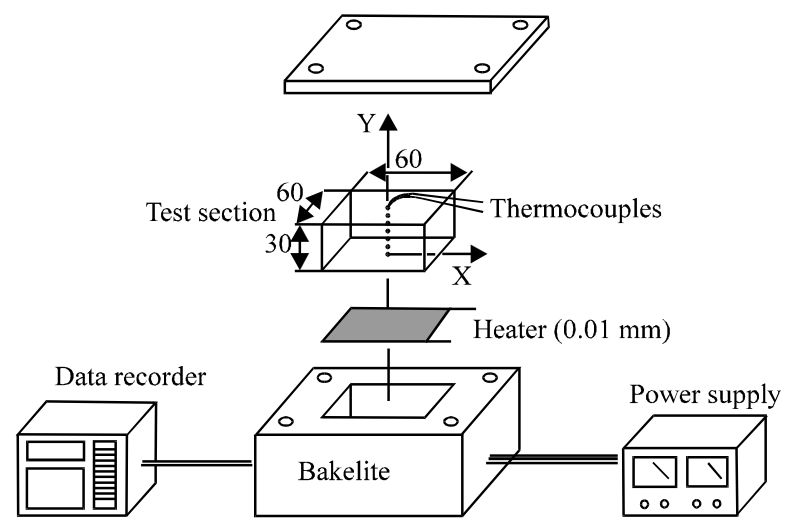

Fig. 2: Heat Transfer Experimental Facility

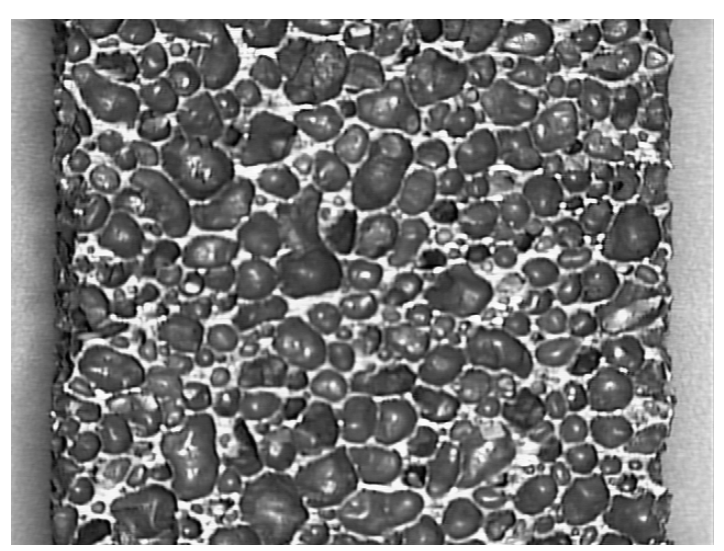

Fig. 3: Photograph of Porous Closed-cell Aluminium Foams

Fine Energy Impact Test: The loading conditions are very different. Under static load conditions, the material deforms slowly. However, if the load is an impact force, the material breaks down suddenly. Accordingly, the effects of impact on porous materials are evaluated. The test machine is designed to perform Charpy-type fineimpact test, with a precision of up to $0.001 \mathrm{~J}$.

Finally, the effects of compressive strength on closed aluminum porous alloys at normal temperature are determined. Figure 1 depicts a flow chart of experiments to elucidate mechanical properties of closed aluminum porous materials.

Heat Transfer Experiments: This study measures steady-state heat transfer. The heat transfer coefficients of the test model are determined experimentally. Figure 2 shows the experimental setup. The test is begun by providing heat steadily to the bottom of the test section; the temperature of the passing air is increased by heat transfer, such that the temperature of the test model also increases gradually. After the measurement is made, the entrance temperature, the exit temperature, the entrance pressure and the exit pressure can be 


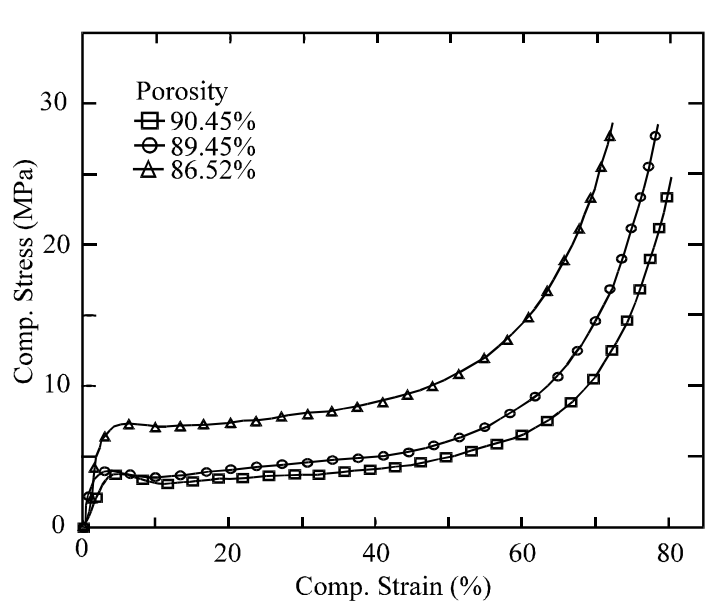

Fig. 4: Compression Curve at Various Porosities

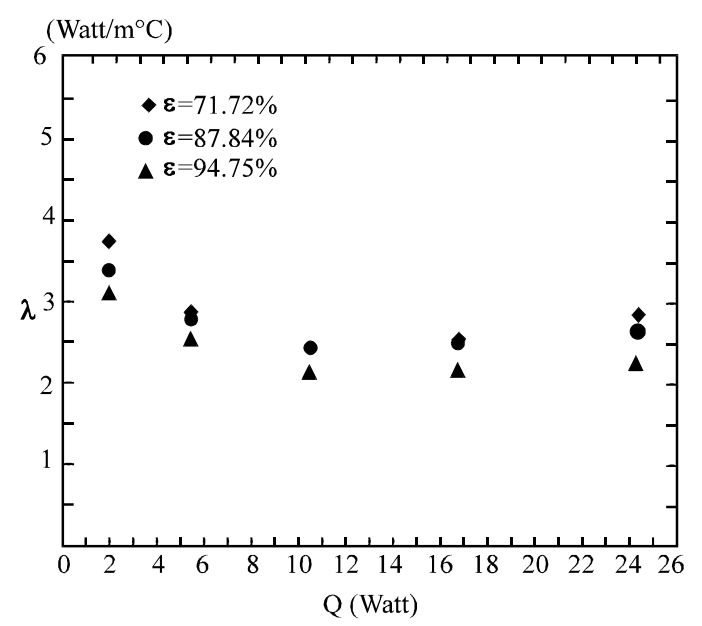

Fig. 5: Thermal Conductivity of Closed-cell Aluminium Foams at Various Input Heat Fluxes

obtained. Then, 12 local temperatures are calculated to determine accurately heat transfer coefficients.

The test section is made from closed-cell aluminum foam. Figure 3 presents the appearance of the test section of size $60 \times 60 \mathrm{~mm}^{3}$. The porosities of the test section are $71.72 \sim 94.75 \%$, respectively. The procedures for determining heat transfer are as follows:

* Choose multi-channel test models of various porosities and arrange the test models and the test section.

* Turn on the compressor, filter, flow meter, manometer, data access system and PC.

* When the air pressure reaches a stable value, open the air valve, adjust the volumetric flow rate and read the data from the flow meter to determine whether it reaches the expected value.

* When the flow field reaches a steady state, take the temperature of the test model and turn on the DC power supply; set the heating power.
* Record the pressure drop between the entrance and the exit, the transient pressure deviation and the transient local wall temperature in the flow direction. After the experimental data are collected, determine the friction factor and heat transfer coefficient.

* Measure the temperature in the entrance region; when the temperature reaches a fixed value, turn off the system. Do the next one test until the temperature of the system reaches room temperature.

* Vary the flow rate; repeat steps 2 6, to determine the effects of heat transfer at various Reynolds numbers.

* Change the porosity of the models and the geometry of the channels; repeat steps 2 7.

Figure 4 plots the compression curves at various porosities. As porosity increases, the porous aluminum alloy exhibits both structural collapse and flat compression. The porosity is critical to determining the conductivity performance of closed-cell aluminum foams at various input heat fluxes. As depicted in Fig. 5, the thermal conductivity variation with input heat flux at various porosities. Axial local temperature distributions from the bottom zones to the top zones are detected using thermocouples and testing times from 1 to $41 \mathrm{~min}$. In all experimental cases, the rate of increase in temperature declines and the temperature reaches a steady state after $41 \mathrm{~min}$. The local temperature distribution along the y-axis direction is transferred to obtain the thermal conductivity of closed-cell Aluminum foams. The $71.72 \%$ porosity of the test section has the bigger thermal conductivity.

\section{CONCLUSIONS}

The cooperative project involves the experimental study of closed-cell porous aluminum foams. The objective of this project is to elucidate the relationship between porosity and efficiency of heat transfer and structural strength. The results of this study support IC packaging cooling applications, reduce the cost of production and replace the traditional pressed fin of low cooling efficiency. The specific achievements of this study are as follows:

* To train some students and provide industrial personnel placements.

* To increase heat transfer efficiency of $3 \mathrm{C}$ electrical packaging elements and improve experimental skills for examining closed-cell porous Aluminum foams, to benefit present technologies and industrial applications.

* To develop a test model with optimal heat transfer performance and mechanical properties; to achieve highly efficient heat transfer in a closed-cell porous medium and to apply for national patents. 


\section{ACKNOWLEDGEMENT}

The authors would like to thank the support by J. King Inc. and the National Science Council of the Republic of China for financially supporting this research under Contract No. NSC 92-2622-E-270-003-CC3.

\section{REFERENCES}

1. Russell, J.S., 1991. Cooperative education: One perspective. J. Professional Issues in Engineering Education and Practice, 117: 319-335.

2. Wen-Shiow, H., 2000. Promoting technological capabilities of small and medium-sized enterprises through industry-university cooperation: Case study of Taiwan machine tool industry. Intl. J. Manufacturing Technol. Manage., 1: 257.

3. Darcy, H., 1856. Les Fontains Publiques de la Ville de Dijon. Paris, Victor Dallmont.
4. Forchheimer, P., 1901. Wasserbewequing durch Boden. Z. Ver. Deusch Ing., 45: 1782-1788.

5. Brinkman, H.C., 1947. A calculation of the viscous force extended by a flowing on a dense swarm of particles. Applied Sci. Res., AL., pp: 2734.

6. Vafai, K. and C.L. Tien, 1981. Boundary and inertia effect on flow and heat transfer in porous media. Intl. J. Heat Transfer, 159-203.

7. Vafai, K., R.L. Alkire and C.L. Tien, 1985. An experimental investigation of heat transfer in variable porosity media. ASME J. Heat Transfer, 107: 642-647.

8. Hunt, M. L. and C.L. Tien, 1988. Effect of thermal dispersion on forced convection in fibrous media. Intl. J. Heat Mass Transfer, 31: 301-309.

9. Hwang, G. J., C.C. Wu and C.H. Chao, 1995. Investigation of non-darcian forced convection in an asymmetric heating sintered porous channels. ASME J. Heat Transfer, 117: 725-732. 